\title{
Foramina in plesiosaur cervical centra indicate a specialized vascular system
}

\author{
Tanja Wintrich ${ }^{1}$, Martin Scaal ${ }^{2}$, and P. Martin Sander ${ }^{1}$ \\ ${ }^{1}$ Bereich Paläontologie, Steinmann-Institut für Geologie, Mineralogie und Paläontologie, Universität Bonn, \\ 53115 Bonn, Germany \\ ${ }^{2}$ Institut für Anatomie II, Universität zu Köln, Joseph-Stelzmann-Str. 9, 50937 Cologne, Germany \\ Correspondence: Tanja Wintrich (tanja.wintrich@uni-bonn.de)
}

Received: 16 August 2017 - Revised: 13 November 2017 - Accepted: 14 November 2017 - Published: 19 December 2017

\begin{abstract}
The sauropterygian clade Plesiosauria arose in the Late Triassic and survived to the very end of the Cretaceous. A long, flexible neck with over 35 cervicals (the highest number of cervicals in any tetrapod clade) is a synapomorphy of Pistosauroidea, the clade that contains Plesiosauria. Basal plesiosaurians retain this very long neck but greatly reduce neck flexibility. In addition, plesiosaurian cervicals have large, paired, and highly symmetrical foramina on the ventral side of the centrum, traditionally termed "subcentral foramina", and on the floor of the neural canal. We found that these dorsal and the ventral foramina are connected by a canal that extends across the center of ossification of the vertebral centrum. We posit that these foramina are not for nutrient transfer to the vertebral centrum but that they are the osteological correlates of a highly paedomorphic vascular system in the neck of plesiosaurs. This is the retention of intersegmental arteries within the vertebral centrum that are usually obliterated during sclerotome re-segmentation in early embryonic development. The foramina and canals are a rare osteological correlate of the non-cranial vascular (arterial) system in fossil reptiles. The adaptive value of the retention of the intersegmental arteries may be improved oxygen transport during deep diving and thermoregulation. These features may have been important in the global dispersal of plesiosaurians.
\end{abstract}

\section{Introduction}

\subsection{Sauropterygian evolution and plesiosaur origins}

Plesiosauria are Mesozoic marine reptiles that had a global distribution almost from their origin in the Late Triassic (Benson et al., 2012) to their extinction at the end of the Cretaceous (Ketchum and Benson, 2010; Fischer et al., 2017). Plesiosauria belong to the clade Sauropterygia and are its most derived and only post-Triassic representatives, being among the most taxonomically diverse of all Mesozoic marine reptiles (Motani, 2009). Sauropterygia originated in the Early Triassic, diversifying into Placodontia and Eosauropterygia. Eosauropterygia include the Pistosauroidea, which in turn include Plesiosauria and nonplesiosaurian pistosauroids (Benson et al., 2012), most notably the genera Yunguisaurus, Pistosaurus, and Augustasaurus (sometimes grouped in the "Pistosauridae") and $\mathrm{Bo}$ bosaurus, the taxon closest to Plesiosauria. All these stem representatives are Middle Triassic and early Late Triassic (Carnian) in age, meaning that a gap of around 30 million years separates them from the plesiosaurs (Benson et al., 2012; Wintrich et al., 2017).

\subsection{The plesiosaur bauplan}

Plesiosauria have a unique bauplan, with an unique mode of aquatic locomotion: four-winged underwater flight using limbs modified into pointed flippers (Ketchum and Benson, 2010; Wintrich et al., 2017). Morphological disparity within the group is mainly found in the evolution of different neck lengths and skull sizes. Neck length evolution involves a long neck at the base of the clade, with at least 35 cervical verte- 
brae, which is unique to "Pistosauridae" and Plesiosauria, all other amniotes having less than 30 cervical vertebrae (Müller et al., 2010). In Pistosauroidea, the increase in neck length evolves by an increase in vertebral number, not by an increase in centrum length as in other well-known long-necked animals, like sauropod dinosaurs (Sander et al., 2011; Taylor and Wedel, 2013). Neck elongation in plesiosaurians culminates in Elasmosauridae with cervical numbers exceeding 70 (O'Keefe, 2001; Zammit et al., 2008; Müller et al., 2010; Noe et al., 2017). The plesiosaurian neck was remarkably stiff (Taylor, 1981; Massare, 1988, 1994; Noe et al., 2017), which appears counterintuitive especially in the long-necked forms.

\subsection{Paired foramina in plesiosaurian cervical vertebrae}

All plesiosaurian cervical vertebrae show a pair of large foramina on the ventral surface of the vertebral centra (Romer, 1956). These foramina are generally termed "subcentral foramina" (Storrs, 1991; Noe et al., 2017). The large, highly symmetrical subcentral foramina are an autapomorphy of plesiosaurs and are found with great regularity in members of the clade (Wintrich et al., 2017; Benson and Druckenmiller, 2014; Storrs, 1991; O'Keefe, 2001), but smaller and less symmetrical foramina are found in some pistosaurids (non-plesiosaurian Pistosauroidea) such as $\mathrm{Au}$ gustasaurus (Rieppel et al., 2002) and Pistosaurus longaevus (Sues, 1987).

The usage of the descriptive term subcentral foramina has a long tradition, and such paired foramina are seen in many taxa of different lineages outside of Sauropterygia. However, the term subcentral foramen is also somewhat of a wastebasket term. In the case of Plesiosauria, foramina subcentralia (subcentral foramina) were defined by Storrs (1991). $\mathrm{He}$ described them as a uniquely derived character shared by virtually all plesiosaurs and as being unknown among other Sauropterygia like pachypleurosaurs, placodonts, and nothosaurid-grade Nothosauriformes. Furthermore, he interpreted the foramina subcentralia as vertebral nutritive foramina in cervical vertebrae. Rothschild and Storrs (2003) hypothesized that the foramina indicated a rich blood supply to the interior of the centra (i.e., acting as nutrient foramina), protecting the vertebrae from decompression syndrome. However, they noted that the foramina showed a "large degree of variability" which is not what we observe (see below).

In addition to these ventral, paired foramina, plesiosaurian cervicals show a pair of large, highly symmetrical foramina on the floor of the neural canal. This character has not received much attention in the literature before (but see Martin and Parris, 2007), probably because it is harder to observe due to its location inside the neural canal. Damaged or sectioned vertebral centra as well as CT scans reveal that the two sets of foramina appear to be connected by two canals that pass through the center of the vertebral centrum. This raises the question as to what occupied the canals in the living animal, with vascular tissue coming to mind.

\subsection{Osteological correlates of postcranial vascular features}

The vascular system in fossil vertebrates is hard to reconstruct because blood vessels such as arteries and veins as well as the heart are not preserved in fossils (see Maldanis et al., 2016, for an exception). In addition, osteological correlates for features of the vascular systems in fossil reptiles remain little studied (Schwarz et al., 2007, p. 181), particularly outside the head. Some basic principles apply, though, that aid in possibly identifying such correlates. In addition, an understanding of the development of the vascular system is important. During development, some arteries in the embryo become remodeled or resorbed, and during growth, bone will grow around arteries but arteries will not lead to bone resorption. This is seen also in the structure of the human skull bone. Note that this is unlike the situation in postcranial skeletal pneumaticity in dinosaurs including birds, where respiratory tissue invades the interior of bone by inducing bone resorption (Wedel, 2009), a process that continues throughout ontogeny.

\subsection{Anatomical interpretation of the paired foramina}

At face value, subcentral foramen is a descriptive term for any foramen on the ventral side of a vertebral centrum. However, there are different vascular structures that may have occupied a subcentral foramen. First, the foramina could each have housed a normal nutrient blood vessel pair, consisting of an artery which enters the bone, delivering the oxygenated blood to the interior of the bone, and a vein draining the bone interior. This is the classical situation seen in long bones with a single large nutrient canal (e.g., Seymour et al., 2012; Nakajima et al., 2014) through which a terminal artery, known as arteria nutricia, enters and then ends inside the bone. Since osteogenesis of the vertebral centrum follows the same rules as that of a long bone, this is a plausible hypothesis for the ventral foramina, as recognized by Storrs (1991). The pairing would then be due to bilateral symmetry of the centrum. The second hypothesis would be that the foramina are the entries for arteries which traverse the vertebral centrum in a dorsoventral (or vice versa) direction. These could develop in two different fashions. The arteries could either have been initially located laterally to the vertebral anlage and subsequently been incorporated into the centrum by the growth expansion of the centrum, as has been described in the posterior caudal and fluke vertebrae of whales by Slijper (1939). Alternatively, they could represent persisting intersegmental arteries which develop in the early embryo and are primarily located within the paraxial mesoderm, first between adjacent somites and later, after somite re-segmentation, inside the vertebral anlage. 


\subsection{Development of the vertebral column and associated vessels}

Development of intersegmental arteries is seen in all vertebrates at an early ontogenetic stage. At the onset of the development of the axial skeleton in vertebrate embryos, in a process called somitogenesis, primary segments form in craniocaudal sequence within the paraxial mesoderm (Benazeraf and Pourquie, 2013). These segments, which are formed synchronously on either side of the neural tube and the notochord, are called somites. While the newly formed somites are epithelial spheres, they subsequently undergo several steps of differentiation to form their tissue derivatives, which include axial skeleton, skeletal muscle, and connective tissue of the trunk. In amniotes, the ventral somite half becomes a mesenchymal mass of cells, the sclerotome, which gives rise to all elements of the vertebral column, including the ribs. The dorsal half, in contrast, forms the dermomyotomal epithelium, which again differentiates into the myotome giving rise to axial muscle and the dermatome giving rise to the connective tissue of the skin. A sub-compartment of the sclerotome, the syndetome, gives rise to vertebral ligaments (Brent et al., 2003) and another sub-compartment, the arthrotome, gives rise to intervertebral joints (Mittapalli et al., 2005; Christ et al., 2007).

Importantly, the somites do not represent the definitive segments of the vertebral column as seen in the individual vertebral bones. In a process called re-segmentation, the adjacent cranial and caudal halves of neighboring sclerotomes unite to give rise to a single vertebra, whereas intervertebral muscles and ligaments arising from the myotome and syndetome maintain the original somitic segmentation pattern. In other words, the derivative of a single somite is not a single vertebra, but a so-called motion segment, which includes two vertebral halves tethered together in a flexible fashion by muscles and ligaments. Without re-segmentation a mobile vertebral column would not be possible (Hall, 2015, chap. 16; Scaal, 2016).

Prior to re-segmentation, neighboring sclerotomes are separated by a pair of embryonic blood vessels called the intersegmental artery and vein, which are ventrally connected to the dorsal aorta and posterior cardinal vein, respectively. In a process which is not yet well understood, these vessels usually disappear or undergo remodeling during the resegmentation process. While at trunk level, the segmental array of vessels is still visible in the adult as, e.g., intercostal vessels, the cervical intersegmental vessels are lost and likely form the vertebral artery and vein.

We hypothesize that in plesiosaurians the intersegmental arteries were retained in cervical vertebrae into the postembryonic stage. Thus, in plesiosaurians, the process of the obliteration of the cervical intersegmental arteries did not happen, and the intersegmental arteries stayed in position and remained functional, extending (following the direction of blood flow) through the center of the cervical vertebral centrum from the ventral surface of the centrum to the floor of the neural canal. Accordingly, we here propose a new term for the large, highly symmetrical paired foramina in plesiosaurian cervicals, i.e., intersegmental artery foramen (IAF), to obtain a more precise terminology in relation to its putative embryological origin. We differentiate between the ventral IAF (vIAF), which corresponds to the traditional subcentral foramen, and the dorsal IAF (dIAF) on the floor of the neural canal. The two foramina are connected by a canal running across the center of ossification of the vertebral centrum, the intersegmental artery canal (IAC). Blood flow in the intersegmental artery located in the IAC would have been from ventral to dorsal, the artery entering through the vIAF and exiting through the dorsal dIAF.

\section{Materials and methods}

\subsection{Materials}

Our study of the internal structure of plesiosaur cervical centra is based on a small but representative sample set. It includes a latest Triassic fetal specimen and two Jurassic vertebrae from two different locations. The Triassic fetal cervical is of uncertain systematic affinity and derives from the newly discovered Rhaetian (latest Triassic) bone bed of Bonenburg, Germany (Sander et al., 2016). The Bonenburg quarry exposes an unusually thick stratigraphic section of Rhaetic sediments, including $11 \mathrm{~m}$ of dark grey mudstones which contain three different bone beds (BB1 to BB3) of the type known from SW England (Storrs, 1994) and southern Germany (Sander et al., 2016). In BB 2, there are several finds of plesiosaur remains, including about 20 isolated plesiosaur vertebrae with and without neural arch in a good state of preservation, including the fetal centrum studied here. The specimen can be assigned to Plesiosauria based on its platycoelous articular surfaces, the ventral keel, and the large paired ventral and dorsal foramina. Similar plesiosaur vertebrae are also known from Rhaetian bone bed localities in France (Fischer et al., 2014) and England (Storrs, 1994). These Triassic vertebrae can be subdivided into different morphotypes that presumably represent different taxa (Sander et al., 2016), but the fetal centrum currently cannot be assigned to any of these. In addition, we included the cervical vertebrae of an articulated skeleton from the Bonenburg locality, the only articulated Triassic plesiosaur skeleton (Wintrich et al., 2017; Sander et al., 2016). The Jurassic vertebrae studied by us include one isolated posterior cervical (SMNS 50845) of an indeterminate plesiosaur from the Posidonienschiefer Formation (Toarcian, Lower Jurassic) of the famous Holzmaden locality, Germany (see also O'Keefe, 2004) and a cervical vertebra that is part of an articulated skeleton of Cryptoclidus eurymerus (STIPB R 324) from the Middle Jurassic Oxford Clay Formation, England (see also Andrews, 1910). 
Finally, we used morphological data on cervical vertebral morphology from the literature, specifically character descriptions compiled for phylogenetic analysis (Benson and Druckenmiller, 2014). Therefore, we transformed the information in the phylogenetic character matrix, consisting of the character descriptions and character states, into the morphological information.

\subsection{Methods}

To test competing hypotheses regarding vascular features, i.e., nutrient canals vs. intersegmental artery canals, the internal morphology of the vertebral centra needs to be revealed, which can be done by $\mu \mathrm{Ct}$ scan and by a transversal histological (petrographic) thin section. Histological sectioning (Fig. 1) of the vertebrae was possible for only one specimen: the posterior cervical (SMNS 50845) from Holzmaden. Of course, the problem with histological sectioning is that this method is destructive and thus was not allowed for the other plesiosaur vertebrae which were used in this study. For the two complete vertebrae, we used high-resolution $\mu \mathrm{Ct}$ scans to obtain virtual sections and reconstruct the IAC (see below).

\subsubsection{Histological sectioning of plesiosaur vertebra}

In the study of the IAC in plesiosaur vertebra, obviously an accurate plane of the section that will intersect the canal is crucial. This will be the transverse plane of the vertebral centrum (perpendicular to the body axis), passing through the center of ossification of the bone (Fig. 1). The proper plane can be detected easily if the floor of the neural canal and thus the dorsal IAF is visible in addition to the ventral surface of the centrum. Before sectioning, vertebra SMNS 50845 was molded and cast for reconstruction after sectioning. Next, the area of the surface trace of the plane of the section was covered by a removable epoxy putty (Technovit) to ensure a clean cut of the outer bone surface. Then, two cuts spaced about $5 \mathrm{~mm}$ apart were placed on either side of the plane of sectioning to obtain a thin slice of bone containing the IAC. After sectioning, the putty was removed from the bone surface and the gap in the bone was filled in with plaster, with the two halves of the bone being held in place by the mold.

The transverse slice of bone was then processed into a petrographic thin section 50 to $80 \mu \mathrm{m}$ in thickness, following the standard procedure for fossil bone most recently outlined by Lamm (2013). The sections were then observed under a Leica DM2500LP polarizing microscope, and digital photomicrographs were taken with a Leica DFC420 color camera mounted on this microscope and edited using the 2007 Leica Image Access EASYLAB 7 software. Overview images were obtained with an Epson V750 high-resolution scanner. Terminology follows Francillion-Vieillot et al. (1990).

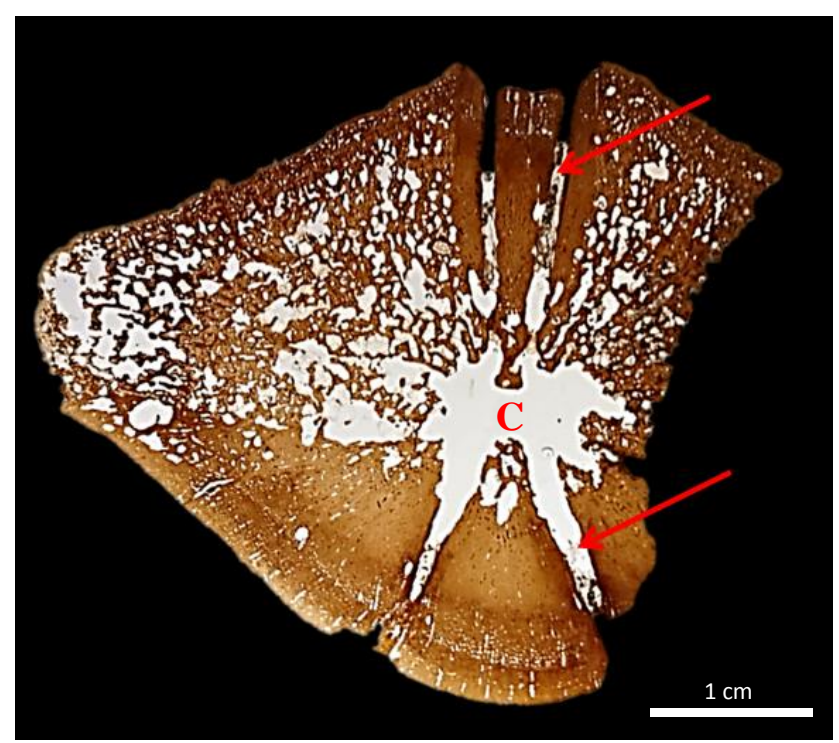

Figure 1. Transversal histological thin section of the posterior cervical vertebra SMNS 50845 from Holzmaden. The left and the right canals appear to meet in the center of ossification (C). However, CT data from other vertebrae suggest that the canals do not meet in the center of ossification, and the apparent connection in this section is probably caused by bone resorption during the formation of the medullary cavity and by damage during grinding of the section.

\subsection{2 $\mu \mathrm{Ct}$ scanning and 3-D reconstruction of plesiosaur vertebra}

The $\mu \mathrm{Ct}$ scans for the virtual sections and canal reconstruction were obtained with the vltomelx s CT scanner manufactured by GE Phoenix X-ray at the Division of Paleontology, Steinmann Institute, University of Bonn. On average, each scan was based on 1200 images. Kilovolt and microampere were set to $190 \mathrm{kV}$ and $150 \mu \mathrm{A}$, respectively, with a voxel size of $79 \mu \mathrm{m}$.

We reconstructed a surface model of the scanned vertebrae with the program Avizo 7.1.1. In order to process the data from the $\mu \mathrm{Ct}$ scan, an image stack was created from the dorsoventral plane (Fig. 2). For this, all $1200 \mu \mathrm{Ct}$ recordings were first uploaded into VG Studio Max and then transformed into image stacks in a JPEG format. The images in the stack were then edited and individual structures of interest were marked and color-coded and became visible, a process known as segmentation. The result is a 3-D model of the vertebra with the course of the canals having been traced (Figs. 2, 3). The modeling software Polyworks was used to visualize the course of the intersegmental arteries (Fig. 3).

\subsubsection{Morphology information based on the phylogenetic matrix}

In order to evaluate the distribution of the ventral vertebral foramina in plesiosaurs, we use published information. 


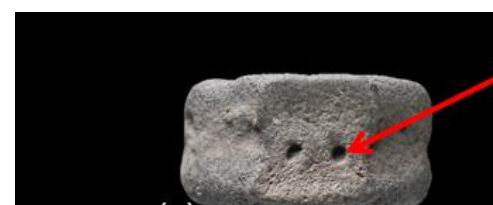

(a)

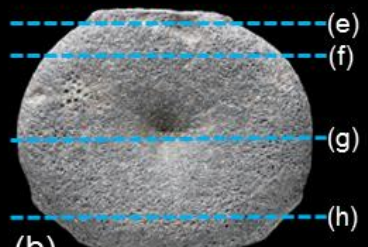

(b)

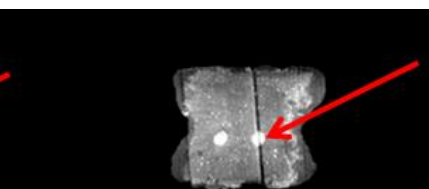

(e)
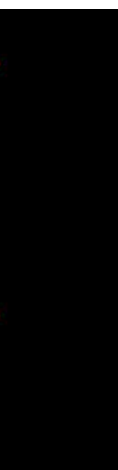

(f)

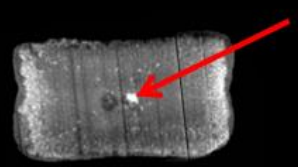

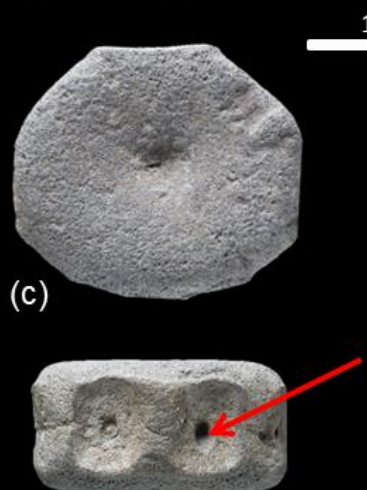

(d)

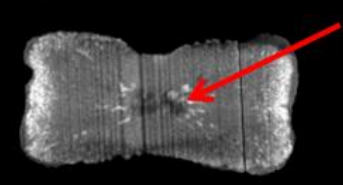

(g)

(h)
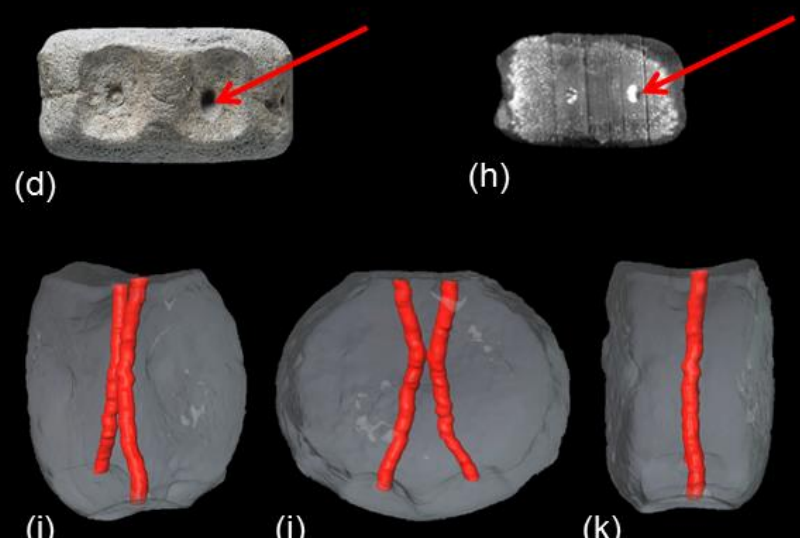

(i)

(j)

(k)

Figure 2. Fetal vertebral centrum of a plesiosaur (LWL-MFN P 64372) from the Rhaetian (latest Triassic) bone bed of Bonenburg (Germany). (a) Dorsal view with paired intersegmental artery foramina on the floor of the neural canal (red arrow). (b) Posterior view of the fetal vertebral centrum with the locations of the $\mu \mathrm{Ct}$ virtual sections (e) to (h) indicated. (c) Anterior view of the centrum. (d) View of the ventral surface of the centrum with paired intersegmental artery foramina (red arrow). Note that the foramina are set in a sunken area. (e-h) $\mu \mathrm{Ct}$ virtual sections through the centrum. The sections also show the orientation of the vascular spaces in the bone, which are arranged radially from the center of ossification. The high-density (white) infillings of these vascular spaces and the intersegmental artery canals are pyrite. The darker fillings are either air or sediment. The red arrows mark the trace of the right canal. (e) Section near the dorsal surface of the vertebral centrum. The paired intersegmental artery foramina as the entrance to the intersegmental artery canals are clearly visible. (f) This section is ventral to (e); the intersegmental artery canal comes closer together. (g) Section through the center of ossification in the middle of the centrum. The canals are close to each other but are still separated. (h) Section through the ventral region of the centrum, where the canals are widely separated. (i-k) Reconstructed paired intersegmental artery canals connecting the paired dorsal and ventral intersegmental artery foramina, with the fetal centrum rendered semitransparent. Reconstruction was performed with Avizo 7.1.1. (i) Oblique anterolateral view. (j) Anterior view. The reconstruction shows clearly that the intersegmental artery canals approach each other one third along their course from dorsal to ventral, close to the center of ossification of the centrum. The connection between the canals is limited, but it gives the canals a characteristic X shape. Note the sunken areas of the ventral surface of the centrum. (k) Lateral view, showing that the canals are located in the anteroposterior plane of symmetry of the centrum, which is equivalent to the original sclerotome border in the embryo. 


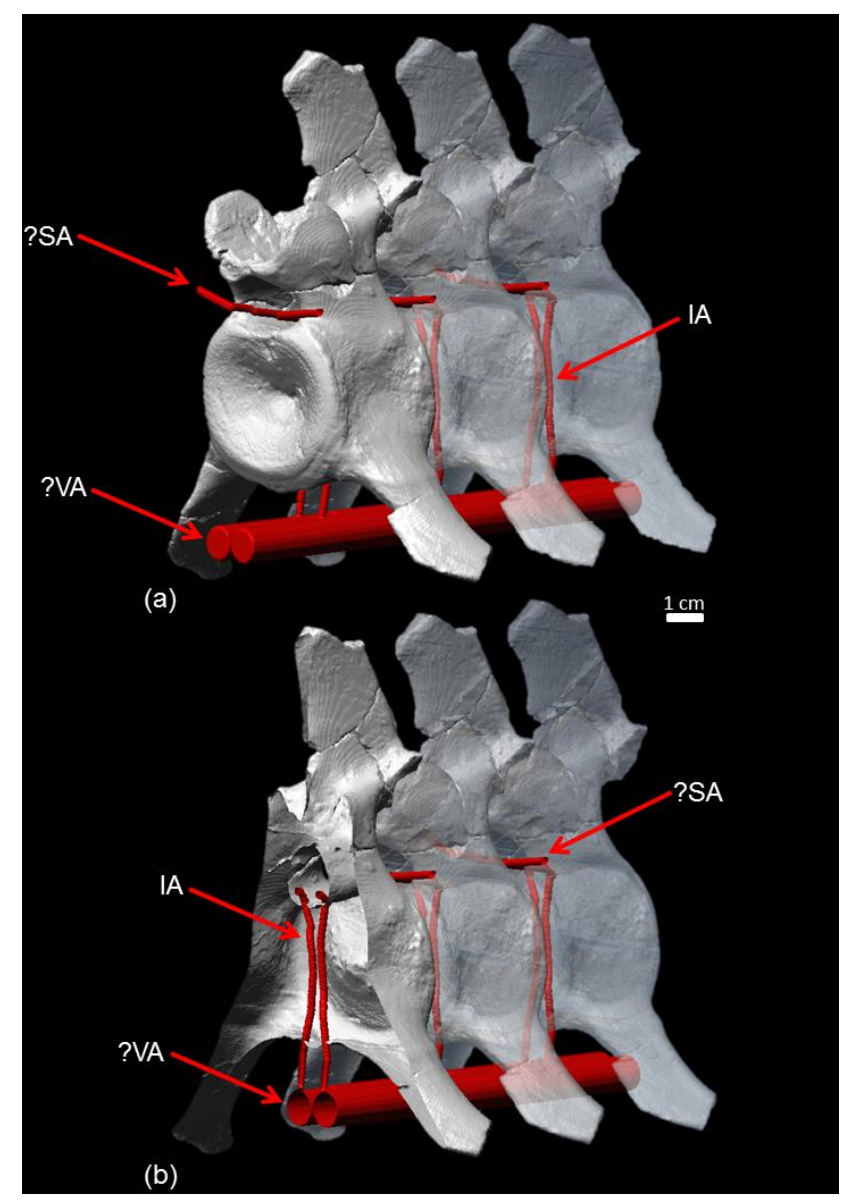

Figure 3. (a) Reconstruction of the arterial system in the plesiosaur neck based on $\mu \mathrm{CT}$ scans, segmentation of the intersegmental artery canals, and modeling of hypothetical vessels in Polyworks. The virtual vertebrae with the intersegmental artery canals are the same cervical (no. 23) of Cryptoclidus IPB R 324 repeated three times. Anterior is to the left. (b) Cutaway view of the anteriormost cervical vertebra of this row with the intersegmental arteries crossing the centrum in dorsoventral direction. Abbreviations: IA - intersegmental artery passing through the vertebral centrum; VA - hypothetical vertebral artery from which the intersegmental arteries branched off; SA - hypothetical spinal artery receiving blood from intersegmental arteries.

Our analysis was based on the phylogenetic character matrix of Benson and Druckenmiller (2014), with updates for this study. The matrix consists of 80 taxa from the Late Triassic to the Late Cretaceous and of 270 characters: the character description and character state description as well as the coding. Eight characters $(141,152,156,166,177,179,187,191)$ of the 270 characters deal with special aspects of vertebral morphology such as nutrient foramina, subcentral foramina, and the number of cervical vertebrae that have implications for the reconstruction of the plesiosaurian neck arterial system.

\section{Results}

\subsection{External morphology}

Based on the analysis of the phylogenetic character list, the cervical vertebrae of all plesiosaurian terminal taxa in the matrix have large, paired symmetrical foramina on the ventral side of the cervical vertebral centra, conforming to the definition of vIAF. In the dorsal vertebrae there is no evidence of subcentral or nutrient foramina. The absence/presence and possible morphology of ventral foramina is unknown in the transitional pectoral vertebrae, which we consider as part of the trunk because of a lack of sufficiently informative material and a lack of published descriptive information.

Both the ventral and the dorsal IAFs are part of character 156 of Benson and Druckenmiller (2014): "Cervical vertebrae, subcentral foramina and foramina on the dorsal surface of the centrum, within the neural canal". This has three states: "both absent (0); both present (1); dorsal foramina present, but subcentral foramina very small or absent (2)". Character 166 is also relevant for this study in that it captures the presence of a midline keel or rounded ventral ridge on the centrum. Beyond this, the shape of the ventral keel and the size of the pits and foramina differ depending on taxon. We observed that in all cervical vertebrae (with the exception of the atlas-axis complex) from the Rhaetic bone beds of Bonenburg and France and in some of the Early Jurassic plesiosaur cervicals (e.g., Benson et al., 2012), there are paired deep ventral pits. At the bottom of the pits are the vIAFs. The cervical vertebrae of the Triassic articulated skeleton (see Wintrich et al., 2017) and the vertebrae of the indeterminate Jurassic plesiosaur SMNS 50845 and of Cryptoclidus IPB 324 have a more even ventral surface without the large keel and deep pits.

All plesiosaur cervical vertebrae in this study show the dIAF on the floor of the neural canal if this is exposed and not covered by sediment. The dIAFs are not coded as separate characters in the Benson and Druckenmiller (2014) matrix but only as part of character 156, as discussed above. dIAFs have rarely been mentioned in morphological descriptions of plesiosaurian cervical centra, as already noted. We observed that the dorsal IAFs are present in all vertebrae personally examined for this study where the neural canal was exposed. State 2 of character 156, "dorsal foramina present, but subcentral foramina very small or absent", is particularly interesting because it correlates with state 0 of character 152 , "number of cervical vertebrae", which is " $<15$ " cervical vertebrae (Benson and Druckenmiller, 2014, appendix S2). This state is seen in the most short-necked pliosaurs Brachauchenius and Stenorhynchosaurus. This very low number of cervicals is highly derived in plesiosaurians and is less than seen in any stem pistosauroid. 


\subsection{Internal structure as revealed by $\mu \mathrm{Ct}$ data, histology, and fracture surfaces}

Both histological sections and segmentation of $\mu \mathrm{Ct}$ data reveal that the left and the right vIAFs and the left and the right dIAF are each connected by a canal that passes through the center of ossification of the centrum. This is also seen in fracture surfaces of centra. In the $\mu \mathrm{Ct}$ images, the canal is visible well and can be traced easily. It is also clear that these two canals do not end in the center of ossification, as a nutrient canal would do, but pass through it. The general appearance of the two canals in transverse sections is X-shaped because the canals gradually diverge from each other towards both the ventral and dorsal intersegmental foramina. The left and the right canals appear to be connected in the central region in the thin section of SMNS 50845, and it appears that the canals merge in a medullary cavity which resorbed the original center of ossification (Fig. 1). However, in the 3-D reconstructions of the fetal vertebra (WMNM P 64372) (Fig. 2) and the adult vertebra (STIPB R 324) (Fig. 3), the canals do not appear to meet in the center of ossification, only approaching each other closely. These conflicting observations may be explained by the loss of trabeculae in the ossification center during the preparation of the thin section of SMNS 50845 (Fig. 1), resulting in an apparent connection between the canals.

\section{Discussion}

\subsection{Interpretation of the paired canals}

Plesiosaur vertebral foramina have been observed and described from so many taxa and have been used as characters in phylogenetic analyses that it is clear that they are a pervasive feature of plesiosaur cervicals (Storrs, 1991; O'Keefe, 2001; Benson and Druckenmiller, 2014; Wintrich et al., 2017), with the possible exception of the pliosaurtype forms (see above). Thus, we feel that our results are representative of all plesiosaur cervicals although we only investigated three specimens in detail. The course of the paired canals through the vertebral centrum would suggest that these structures originally housed continuous arteries traversing the vertebral centrum in ventrodorsal direction, which opens up the possibility that they contained persisting intersegmental arteries, not nutrient ones, which would have ended within the central region of the vertebra. Furthermore, the crossing of the vertebral centrum is a feature which we argue should originate at an early developmental stage. This is because in the case of nutritive canals, the vascular system does spread into bone tissue (as mentioned above), whereas in continuous blood vessels, the bone tissue grows around the vessels instead. It is also known that bone tissue cannot resorb or displace features of the vascular system such as arteries because osteoclasts only resorb mineralized surfaces
(Hall, 2015, chap. 15). This suggests that the arteries were already present in the vertebral primordium at the stage in early development when the sclerotomes were re-segmented and, subsequently, the cartilage primordia of the centra of the vertebra were formed. As the primordium of the centrum grew and ossified, the arteries and with them the canals also enlarged in size. The divergence of the canals is explained by the retention of the homologous locations inside the centrum and on its surface as ventral and dorsal intersegmental foramina.

While posterior caudal and fluke vertebrae of extant whales have similar canals piercing the vertebral centra and housing arteries (Slijper, 1939), their morphology and origin is rather different, as described in detail by Slijper (1939) and confirmed by a study of the tail segment of a complete adult skeleton of the bottlenose dolphin Tursiops truncatus (LACM 97723; Slijper, 1939). First of all, the paired canals do not pass through the center of ossification of the centra but in an arch around it. This indicates that the vessels were incorporated into vertebrae only in the juvenile, not in the embryo. Second, it can be observed that the canals form by the gradual (from anterior to posterior, not ontogenetically) incorporation of an artery lateral to the centrum. The artery more anteriorly only pierces the transverse process and then more posteriorly becomes incorporated deeply into the centrum. The canals in the whale caudal vertebrae are thus not homologous to those in the plesiosaurian cervical vertebrae. A possible exception to the non-homology of the canals in plesiosaurs and whales may be the vertebra depicted by Houssaye et al. (2015, fig. 14) in which canals are seen passing dorsoventrally through the center of ossification. However, these canals do not show the strong symmetry that is so typical of plesiosaurs. The lack of symmetry in the canals in Basilosaurus suggest that they do not represent persisting intersegmental arteries but originated later in ontogeny.

\subsection{Developmental retention of the intersegmental arteries in plesiosaurs}

An understanding of the arteries crossing the primordium requires some considerations of the embryonic development of the vascular system of the head, neck, and body stem. In terms of the evolutionary patterns in the framework of heterochrony, the retention of intersegmental arteries in plesiosaurians would have to be considered a case of extreme paedomorphosis (Alberch et al., 1979; McNamara, 1997). Also, regionalization of the body is an important aspect to consider because the molecular boundary between the neck and the trunk is distinct (Müller et al., 2010) and highly conserved: the cervical column in the mouse, crocodile, and chicken shows expression of Hox4 and Hox 5 but lacks expression of Hox6 genes (Böhmer et al., 2015), and this pattern is also observed in legless tetrapods such as snakes and Gymnophiona (Woltering et al., 2009). 
In the embryo, a paired primary dorsal aorta differentiates by vasculogenesis and is located underneath the paraxial mesoderm. The primary dorsal aortae gradually change position from lateral to medial. Eventually, both dorsal aortae fuse in the midline of the embryo ventral to the notochord, which leads to the formation of a single large median aorta (Wiegreffe et al., 2007; Garriock et al., 2010). Initially, the intersegmental arteries branch off in dorsal direction from the paired dorsal aortae, passing in between the sclerotomes before re-segmentation. Their subsequent development is not well studied. In the trunk at thoracic levels, they relocate laterally to form the intercostal arteries. In the neck, they seem to obliterate in their proximal part during re-segmentation, whereas their distal part outside the vertebral centra fuses with neighboring segments to form the vertebral artery (Arey, 1924, p. 212).

Importantly, we found evidence for intersegmental artery retention only in the cervical vertebral centra, not in the dorsal vertebral centra. Thus, if plesiosaurians retained intersegmental arteries, then the question arises as to which vessels these intersegmental arteries were connected to. As mentioned above, in principle the intersegmental arteries in extant embryos arise from the paired aortae. In the neck, however, they form longitudinal anastomoses which give rise to the aorta vertebralis, while the connections to the dorsal aorta become obliterated. In snakes like Elaphe obsoleta, the Arteria vertebralis, in turn, emits segmental branches which reach the spinal canal where they anastomose longitudinally to give rise to the A. spinalis and associated vessels (Zippel et al., 1998). As in plesiosaurs the intersegmental vessels lead to the spinal canal. Thus, we postulate that in analogy to the anatomy of snakes, the intersegmental vessels join the longitudinal spinal artery in the spinal canal. As to their origin, we speculate that they branch off a longitudinal vertebral artery which has arisen from the paired dorsal aortae of earlier embryonic stages (Fig. 3). As no fossil correlates are preserved, this scenario remains forcibly speculative, but the vascular anatomy as postulated here would likely not be problematic in an adult plesiosaurian from a functional point of view. The extreme evolutionary neck elongation by an increase in segment number (not segment elongation) in the plesiosaur line (including pistosaurids) may have required or have been facilitated by a developmental retention of strong bilateral arteries derived from the paired aortae and with it the intersegmental arteries arising from them.

We shall now evaluate the hypotheses explaining why plesiosaurians did not resorb the intersegmental arteries, retaining the embryonic vascular system. The first hypothesis involves developmental constraints linked to the uniquely high number of cervicals in plesiosaurs (the low number of pliosaur-type plesiosaurs being secondarily derived). This, like any other hypothesis explaining the persistence of intersegmental arteries, has to be consistent with the lack of IAF in the dorsal and presumably pectoral vertebrae, the numbers of which are not unusually high in plesiosaurians compared to other amniotes (Müller et al., 2010; Coffin and Poole, 1988).

The uniquely high number of cervical vertebrae means that in the plesiosaurian embryo there was also a uniquely high number of cervical somites and sclerotomes. As noted above, no other vertebrate group evolved such an enormously long neck via an increase in the number of segments, i.e., vertebrae (Müller et al., 2010). A model for understanding the development of the very high number of cervical segments in plesiosaurians might be the segmentation process in snakes, that have evolved very high numbers of dorsal segments. There, it has been shown that the molecular mechanisms of somitogenesis are principally the same as in vertebrates with lower segment numbers, but that somitogenesis proceeds much faster leading to initially smaller somites which, however, later on grow to a normal size relative to the size of the snake species concerned (Gomez et al., 2008). In snakes, the extremely high number of dorsal vertebrae ("precloacal" in morphological terminology) correlates with a corresponding extension the expression of thorax-specific Hox genes, like Hox6, along the body axis (Cohn and Tickle, 1999). It is therefore likely that in long-necked plesiosaurian embryos, cervical Hox gene expression was maintained over many segmentation rounds, which probably occurred relatively rapidly when compared to short-necked species (both ancestral to plesiosaurians and derived within plesiosaurians, i.e., in the pliosaur type). A potential link between frequency and speed of somitogenesis on the one hand and the formation of intersegmental vessels on the other hand is yet unknown.

Furthermore, we do not know if plesiosaurians developed paired vertebral arteries arising from the aorta in addition to retaining the intersegmental arteries. These vertebral arteries would have extended along (?) the vertebral centrum, with nutrient arteries branching off and vascularizing the vertebral body through lateral nutrient foramina as seen in mammals (Rothman and Simeone, 1975). Such lateral nutrient foramina are common in marine mammals but differ from the vIAF of plesiosaurians in their smaller size, larger number, and asymmetrical irregular placement.

In the tuatara, Sphenodon punctatus, there are also paired foramina in the caudal centra, and classical embryological research (Schauinsland, 1906, fig. 323) clearly shows a paired artery extending dorsoventrally across the cartilage primordium of the caudal centrum in dolphins (Schauinsland, 1906).

\subsection{Functional interpretation and adaptive value of intersegmental arteries}

The probable persistence of intersegmental arteries and the possible presence of vertebral arteries in the plesiosaurian neck raise the question of the function and adaptive value of these features. Several advantages can be hypothesized, beginning with what is known in the few extant amniotes that 
seemingly retain intervertebral arteries. In the tree-climbing rat snake Elaphe obsoleta, intersegmental arteries are retained in the neck region. This is interpreted as an adaptation for maintaining cerebral blood flow in spite of gravitational stress, e.g., during climbing (Zippel et al., 1998). This observation offers an exciting parallel to the situation in plesiosaurians, where high hydrostatic pressure during deep diving $(>200 \mathrm{~m})$ might have required segmental transvertebral arterial anastomoses to provide sufficient cerebral blood supply. If intravertebral intersegmental arteries were developed as additional arteries in plesiosaurians, there would be a higher oxygen transport capacity than in a single pair of intersegmental arteries per vertebra. This capacity would enable faster transport of oxygen for storage into muscles during deep diving. A similar hypothesis was presented by Rothschild and Storrs (2003), suggesting that the increased blood flow to the interior of the centra protected them from avascular necrosis. However, this hypothesis is not consistent with the persistence of intersegmental arteries because they would not have supplied the interior of the centrum with extra blood.

Other functional hypotheses explaining the retention of intersegmental arteries related to deep diving involve the protection from compression of the blood vessels by their location in canals in the vertebrae. If there were anastomoses with the vertebral arteries, an increase in the number of segments would mean more anastomoses and again greater transport capacity. Other, as yet less easily hypothesized advantages might be related to the compression of the upper respiratory and digestive tracts. Hypotheses involving a long neck and high cervical vertebral numbers invite future tests based on the comparison with the cervical vertebral column of shortnecked plesiosaurian (i.e., pliosaur-type) that evolved several times in the history of plesiosaurians, together with the seeming loss of ventral IAF (see phylogenetic data matrix in Benson and Druckenmiller, 2014).

\subsection{Persistent intersegmental arteries: increasing adaptation to a pelagic lifestyle?}

As discussed above, IAFs are a unique character of plesiosaurians. However, it is not only plesiosaurs that have paired foramina on the ventral side of their cervical vertebrae. The non-plesiosaurian pistosauroids Pistosaurus longaevus and Augustasaurus hagdorni also show paired foramina (Sues, 1987; Rieppel et al., 2002), whereas Yunguisaurus liae (Sato et al., 2014) and Bobosaurus forojuliensis (Dalla Vecchia, 2006) do not share the character. The reason for this could be the degree of adaptation to the pelagic habitat and colder waters in the pistosauroid lineage (Krahl et al., 2013). Augustasaurus is the first and only unequivocal non-plesiosaurian pistosauroid which is found outside the Tethys realm on the western coast of North America (Sander et al., 1997). Possible other non-plesiosaurian pistosauroids outside the Tethys are Corosaurus from Wyoming (Storrs,
1991) and Alexeyisaurus from Arctic Russia (Sennikov and Arkhangelsky, 2010), but the systematic position of the former is unstable, and the latter is too poorly preserved for a reliable systematic assignment.

Since available evidence suggests that sauropterygians originated in the Tethys (Neenan et al., 2013) and all other Triassic pistosauroids are known from this realm (Benson et al., 2012), the ancestors of Augustasaurus must have emigrated from the warm equatorial waters of the Tethys and either dispersed around the polar northern or southern coast of Pangaea or across Panthalassa. Either way, an elevated metabolic rate and endothermy appear to be prerequisites for this dispersal (Krahl et al., 2013). The persistence of intersegmental arteries in the neck could have been incipiently present in Augustasaurus and would have been useful for improved thermoregulation in the colder pelagic waters of Panthalassa. If pistosauroids dispersed across Panthalassa to reach western North America, several other adaptations would be necessary. These include, for example, cruising adaptations in aquatic locomotion by underwater flight. Also, the ability of deep diving (see above) is an adaptation to the pelagic habitat because prey there is sparser and more evenly distributed across the water column (and not at the sea bottom) than in coastal habitats. Plesiosaurians show all these features of adaptation to a pelagic habitat and not surprisingly are globally distributed at least by the Middle Jurassic (Bardet et al., 2014).

\section{Conclusions}

Plesiosaurians cervical vertebrae bear a peculiar set of bilaterally paired foramina on their ventral side, matched by paired foramina on the floor of the neural canal. CT scanning, thin sectioning, and the observation of fracture surfaces reveals that the foramina on each side are connected by a canal that passes through the center of ossification of the vertebral centrum. The foramina and canals thus did not house nutritive blood vessels supplying the center of the bone but must have contained blood vessels that entered ventrally and exited dorsally. The location of the canals in the anteroposterior middle of the centra, their high bilateral symmetry, and their course through the center of ossification suggests that the blood vessels contained in the canals represent an embryonic vascular feature, the intersegmental arteries that persisted into the adult. The plesiosaurian intersegmental arteries became incorporated into the primordium of the vertebral centrum during re-segmentation in the embryonic axial skeleton and thus were not resorbed, unlike in almost all other amniotes. The persistence of the intersegmental arteries is correlated to, and presumably linked with, the uniquely high number of cervical vertebrae, stiffening of the neck, and increased pelagic adaptation in plesiosaurs compared to nonplesiosaurian sauropterygians. Possible adaptive advantages 
of the persistent intersegmental arteries must be sought in deep diving and in thermoregulation in the neck.

Data availability. All data needed to evaluate the conclusions in the paper are present in the paper. Additional data related to this paper may be requested from the authors.

The specimens and thin sections on which this study is based are reposited in the following institutions, here listed with their abbreviations: LWL-MFN - LWL- Museum für Naturkunde, Muünster, Germany; SMNS - Staatliches Museum für Naturkunde, Stuttgart, Germany; STIPB - Steinmann Institute Paleontology Collection, University of Bonn, Bonn, Germany.

Competing interests. The authors declare that they have no conflict of interest.

Special issue statement. This article is part of the special issue "Secondary adaptation of tetrapods to life in water - Proceedings of the 8th International Meeting, Berlin 2017'. It is a result of the 8th International Meeting on the Secondary Adaptation of Tetrapods to Life in Water, Berlin, Germany, 3-8 April 2017.

Acknowledgements. First and foremost we thank Michael Mertens of Schwaney (North Rhine-Westphalia, Germany) for his untiring efforts in collecting marine reptiles from the Rhaetian bone beds of Bonenburg and facilitating their transfer to the LWL-MFN collections. We thank Olaf Dülfer (Bonn) for help with specimen preparation, Georg Oleschinski (Bonn) for photography, and Rico Schellhorn (Bonn) for help with illustrations and discussion. Reviews by Alexandra Houssaye and two anonymous reviewers are gratefully acknowledged. This project was funded by the Deutsche Forschungsgemeinschaft (DFG, grant number SA 469/47-1) and by the LWL-Museum für Naturkunde (Münster, Germany) through the archeological and paleontological heritage mitigation scheme of the State of North Rhine-Westphalia.

Edited by: Florian Witzmann

Reviewed by: Alexandra Houssaye and two anonymous referees

\section{References}

Alberch, P., Gould, S. J., Oster, G. F., and Wake, D. B.: Size and shape in ontogeny and phylogeny, Paleobiology, 5, 296-317, 1979.

Andrews, C. W.: A descriptive catalogue of the marine reptiles of the Oxford Clay, The British Museum (Natural History) London, London, 202 pp., 1910.

Arey, L. B.: Developmental Anatomy. W. B. Saunders Company, Philadelphia and London, 1924.

Bardet, N., Falconnet, J., Fischer, V., Houssaye, A., Jouve, S., Pereda Suberbiola, X., Pérez-García, A., Rage, J.-C., and Vincent, P.: Mesozoic marine reptile palaeobiogeography in re- sponse to drifting plates, Gondwana Research, 26, 869-887, https://doi.org/10.1016/j.gr.2014.05.005, 2014.

Bénazéraf, B. and Pourquié, O.: Formation and segmentation of the vertebrate body axis, Annu. Rev. Cell Dev. Bi., 29, 1-26, 2013.

Benson, R., Evans, M., and Druckenmiller, P.: High diversity, low disparity and small body size in plesiosaurs (Reptilia, Sauropterygia) from the Triassic - Jurassic boundary, PLoS ONE, 7, e31838, https://doi.org/10.1371/journal.pone.0031838, 2012.

Benson, R. B. J. and Druckenmiller, P. S.: Faunal turnover of marine tetrapods during the Jurassic-Cretaceous transition, Biol. Rev., 89, 1-23, https://doi.org/10.1111/brv.12038, 2014.

Böhmer, C., Rauhut, O., and Wörheide, G.: Correlation between Hox code and vertebral morphology in archosaurs, Proc. Roy. Soc. B, 282, 20150077, https://doi.org/10.1186/s40851-0170069-4, 2015.

Brent, A. E., Schweitzer, R., and Tabin, C. J.: A somitic compartment of tendon progenitors, Cell, 113, 235-248, 2003.

Christ, B., Huang, R., and Scaal, M.: Amniote somite derivatives, Dev. Dynam., 236, 2382-2396, 2007.

Coffin, J. D. and Poole, T. J.: Embryonic vascular development: immunohistochemical identification of the origin and subsequent morphogenesis of the major vessel primordia in quail embryos, Development, 102, 735-748, 1988.

Cohn, M. J. and Tickle, C.: Developmental basis of limblessness and axial patterning in snakes, Nature, 399, 474-479, 1999.

Dalla Vecchia, F. M.: A new sauropterygian reptile with plesiosaurian affinity from the Late Triassic of Italy, Rivista Italiana di Paleontologia e Stratigrafia, 112, 207-225, 2006.

Fischer, V., Cappetta, H., Vincent, P., Garcia, G. r., Goolaerts, S., Martin, J. E., Roggero, D., and Valentin, X.: Ichthyosaurs from the French Rhaetian indicate a severe turnover across the Triassic-Jurassic boundary, Naturwissenschaften, 101, 10271040, https://doi.org/10.1007/s00114-014-1242-7, 2014.

Fischer, V., Benson, R. B. J., Zverkov, N. G., Soul, L. C., Arkhangelsky, M. S., Lambert, O., Stenshin, I. M., Uspensky, G. N., and Druckenmiller, P. S.: Plasticity and convergence in the evolution of short-necked plesiosaurs, Current Biology, 27, 1667-1676.e3, https://doi.org/10.1016/j.cub.2017.04.052, 2017.

Francillon-Vieillot, H., de Buffrénil, V., Castanet, J., Geraudie, J., Meunier, F., Sire, J. Y., Zylberberg, L., and de Ricqles, A.: Microstructure and mineralization of vertebrate skeletal tissues, in: Skeletal Biomineralization: Patterns, Processes and Evolutionary Trends, Vol. 1, edited by: Carter, J. G., Van Nostrand Reinhold, New York, 471-530, 1990.

Garriock, R. J., Czeisler, C., Ishii, Y., Navetta, A. M., and Mikawa, T.: An anteroposterior wave of vascular inhibitor downregulation signals aortae fusion along the embryonic midline axis, Development, 137, 3697-3706, 2010.

Gomez, C., Özbudak, E. M., Wunderlich, J., Baumann, D., Lewis, J., and Pourquié, O.: Control of segment number in vertebrate embryos, Nature, 454, 335, 2008.

Hall, B. K.: Bones and Cartilage. 2nd Edition. Developmental and Evolutionary Skeletal Biology, Academic Press, San Diego, 2015.

Houssaye, A., Tafforeau, P., De Muizon, C., and Gingerich, P. D.: Transition of Eocene whales from land to sea: evidence from bone microstructure, PloS ONE, 10, e0118409, https://doi.org/10.1371/journal.pone.0118409, 2015. 
Ketchum, H. F. and Benson, R. B.: Global interrelationships of Plesiosauria (Reptilia, Sauropterygia) and the pivotal role of taxon sampling in determining the outcome of phylogenetic analyses, Biol. Rev., 85, 361-392, https://doi.org/10.1111/j.1469185X.2009.00107.x, 2010.

Krahl, A., Klein, N., and Sander, P. M.: Evolutionary implications of the divergent long bone histologies of Nothosaurus and Pistosaurus (Sauropterygia, Triassic), BMC Evolutionary Biology, 13, 1-23, 2013.

Lamm, E.-T.: Chapter 4 - Preparation and sectioning of specimens, in: Bone Histology of Fossil Tetrapods. Advancing Methods, Analysis, and Interpretation, edited by: Padian, K. and Lamm, E.-T., University of California Press, Berkeley, 55-160, 2013.

Lara Maldanis, L., Carvalho, M., Almeida, M. R., Freitas, F. I., de Andrade, J. A. F. G., Nunes, R. S., Rochitte, C. E., Poppi, R. J., Freitas, R. O., Rodrigues F., Siljeström S., Lima, F. A., Galante, D., Carvalho, I. S., Perez, C. A., de Carvalho, M. R., Bettini, J., Fernandez, V. and Xavier-Neto, J.: Heart fossilization is possible and informs the evolution of cardiac outflow tract in vertebrates, Elife, 5, e14698, https://doi.org/10.7554/eLife.14698, 2016.

Martin, J. E. and Parris, D. C. (Eds.).: The Geology and Paleontology of the Late Cretaceous Marine Deposits of the Dakotas, Geological Society of America Special Paper 427, 2007.

Massare, J. A.: Swimming capabilities of Mesozoic marine reptiles, Paleobiology, 14, 187-205, 1988.

Massare, J. A. and Callaway, J. M.: Cymbospondylus (Ichthyosauria: Shastasauridae) from the Lower Triassic Thaynes Formation of southeastern Idaho, J. Vertebr. Paleontol., 14, 139-141, 1994.

McNamara, K. J.: Shapes of Time. The Evolution of Growth and Development, Johns Hopkins University Press, Baltimore, 342 pp., 1997.

Mittapalli, V. R., Huang, R., Patel, K., Christ, B., and Scaal, M.: Arthrotome: a specific joint forming compartment in the avian somite, Dev. Dynam., 234, 48-53, 2005

Motani, R.: The evolution of marine reptiles, Evolution: Education and Outreach, 2, 224-235, 2009.

Müller, J., Scheyer, T. M., Head, J. J., Barrett, P. M., Werneburg, I., Ericson, P. G. P., Pol, D., and Sánchez-Villagra, M. R.: Homeotic effects, somitogenesis and the evolution of vertebral numbers in recent and fossil amniotes, P. Natl. Acad. Sci. USA, 107, 21182123, 2010.

Nakajima, Y., Hirayama, R., and Endo, H.: Turtle humeral microanatomy and its relationship to lifestyle, Biol. J. Linn. Soc., 112, 719-734, 2014.

Neenan, J. M., Klein, N., and Scheyer, T. M.: European origin of placodont marine reptiles and the evolution of crushing dentition in Placodontia, Nature Communications, 4, 1-7, https://doi.org/10.1038/ncomms2633, 2013.

Noè, L. F., Taylor, M. A., and Gómez-Pérez, M.: An integrated approach to understanding the role of the long neck in plesiosaurs, Acta Palaeontologica Polonica, 62, 137-162, 2017.

O'Keefe, F. R.: Preliminary description and phylogenetic position of a new plesiosaur (Reptilia: Sauropterygia) from the Toarcian of Holzmaden, Germany, J. Paleontol., 78, 973-988, 2004.

Rieppel, O., Sander, P. M., and Storrs, G. W.: The skull of the pistosaur Augustasaurus from the Middle Triassic of northwestern Nevada, J. Vertebr. Paleontol., 22, 577-592, 2002.
Romer, A. S.: Osteology of the Reptiles, The University of Chicago Press, Chicago, 772 pp., 1956.

Rothman, R. H. and Simeone, F. A: The spine. Vol. 1. WB Saunders, Philadelphia, 1975.

Rothschild, B. M. and Storrs, G. W.: Decompression syndrome in plesiosaurs (Sauropterygia: Reptilia), J. Vertebr. Paleontol., 23, 324-328, 2003.

Sander, P. M., Christian, A., Clauss, M., Fechner, R., Gee, C., Griebeler, E. M., Gunga, H.-C., Hummel, J., Mallison, H., Perry, S., Preuschoft, H., Rauhut, O., Remes, K., Tütken, T., Wings, O., and Witzel, U.: Biology of the sauropod dinosaurs: the evolution of gigantism, Biol. Rev. of the Cambridge Philosophical Society, 86, 117-155, 2011.

Sander, P. M., Rieppel, O. C., and Bucher, H.: A new pistosaurid (Reptilia: Sauropterygia) from the Middle Triassic of Nevada and its implications for the origin of plesiosaurs, J. Vertebr. Paleontol., 17, 526-533, 1997.

Sander, P. M., Wintrich, T., Schwermann, A. H., and Kindlimann, R.: Die paläontologische Grabung in der Rhät-Lias-Tongrube der Fa. Lücking bei Warburg-Bonenburg (Kr. Höxter) im Frühjahr 2015, Geologie und Paläontologie in Westfalen, 88, 11-37, 2016.

Sato, T., Zhao, L.-J., Wu, X.-C., and Li, C.: A new specimen of the Triassic pistosauroid Yunguisaurus, with implications for the origin of Plesiosauria (Reptilia, Sauropterygia), Palaeontology, 57, 55-76, 2014.

Scaal, M.: Early development of the vertebral column, Seminars in Cell and Developmental Biology, 49, 83-91, 2016.

Schauinsland, H. H.: Beiträge zur Entwicklungsgeschichte und Anatomie der Wirbeltiere, E. Nägele, Stuttgart, 168 pp., 1903.

Schauinsland, H. H.: Die Entwicklung der Wirbelsäule nebst Rippen und Brustbein, in: Handbuch der vergleichenden und experimentellen Entwicklungslehre der Wirbeltiere, edited by: Hertwig, O., Gustav Fischer Jena, Bd. 3 Teil 2, 339-562, 1906.

Schwarz, D., Frey, E., and Meyer, C. A.: Pneumaticity and softtissue reconstructions in the neck of diplodocid and dicraeosaurid sauropods, Acta Palaeontologica Polonica, 52, 167-188, 2007.

Sennikov, A. G. and Arkhangelsky, M. S.: On a typical Jurassic sauropterygian from the Upper Triassic of Wilczek Land (Franz Josef Land, Arctic Russia), Paleontol. J., 44, 567-572, 2010.

Seymour, R. S., Smith, S. L., White, C. R., Henderson, D. M., and Schwarz-Wings, D.: Blood flow to long bones indicates activity metabolism in mammals, reptiles and dinosaurs, Proc. Roy. Soc. B, 279, 451-456, 2012.

Slijper, E. J.: Pseudorca crassidens (Owen), ein Beitrag zur vergleichenden Anatomie der Cetaceen, Zoologische Mededeelingen Rijksmuseum van Natuurlijke Historie Leiden, 21, 241-366, 1939.

Storrs, G. W.: Anatomy and relationships of Corosaurus alcovensis (Diapsida: Sauropterygia) and the Triassic Alcova Limestone of Wyoming, Bulletin of the Peabody Museum of Natural History, Yale University, 44, 1-151, 1991.

Storrs, G. W.: Fossil vertebrate faunas of the British Rhaetian (latest Triassic), Zool. J. Linn. Soc., 112, 217-259, https://doi.org/10.1111/j.1096-3642.1994.tb00319.x, 1994.

Sues, H.-D.: Postcranial skeleton of Pistosaurus and interrelationships of the Sauropterygia (Diapsida), Zool. J. Linn. Soc., 90, 109-131, 1987.

Taylor, M. A.: Plesiosaurs - rigging and ballasting, Nature, 290, 628-629, 1981. 
Taylor, M. P. and Wedel, M. J.: Why sauropods had long necks; and why giraffes have short necks, PeerJ, 1:e36, https://doi.org/10.7717/peerj.36, 2013.

Wedel, M. J.: Evidence for bird-like air sacs in saurischian dinosaurs, J. Exp. Zool. A, 311, 1-18, 2009.

Wiegreffe, C., Christ, B., Huang, R., and Scaal, M.: Sclerotomal origin of smooth muscle cells in the wall of the avian dorsal aorta, Dev. Dynam., 236, 2578-2585, 2007.

Wintrich, T., Hayashi, S., Houssaye, A., Nakajima, Y., and Sander, P. M.: A Triassic plesiosaurian skeleton and bone histology inform on evolution of a unique body plan, Sci. Adv., 3, e1701144, https://doi.org/10.1126/sciadv.1701144, 2017.
Woltering, J. M., Vonk, F. J., Müller, H., Bardine, N., Tuduce, I. L., de Bakker, M. A., Knöchel, W., Sirbu, O., Durston, A. J., and Richardson, M. K.: Axial patterning in snakes and caecilians: evidence for an alternative interpretation of the Hox code, Dev. Biol., 332, 82-89, 2009.

Zammit, M., Daniels, C. B., and Kear, B. P.: Elasmosaur (Reptilia: Sauropterygia) neck flexibility: Implications for feeding strategies, Comp. Biochem. Physiol., Part A, 150, 124-130, 2008.

Zippel, K. C., Lillywhite, H. B., and Mladinich, C. R. J.: Contribution of the vertebral artery to cerebral circulation in the rat snake Elaphe obsoleta, J. Morphol., 238, 39-51, 1998. 